\title{
THE DERIVATION OF PRODUCTION LOT SIZING WITH IMPERFECT QUALITY, INSPECTION AND REWORK USING AN ALGEBRAIC APPROACH
}

\author{
CEBİRSEL BİR YAKLAŞIM KULLANILARAK DÜŞÜK KALİTE, \\ TARAMA, YENIDEN İ̧LEME/TAMİR ETME İLE ÜRETIM PARTİ \\ HACMININ ELDE EDILMESI
}

\author{
Harun ÖZTÜRK ${ }^{*}$
}

\begin{abstract}
Many researchers use traditional computing processes that take the first and second-order partial derivatives to obtain closed form mathematical equations for the optimal order quantity or the optimal production quantity. However, this paper provides an algebraic approach to solving the production lot-sizing problem in an imperfect production inventory system where an inspection process is conducted during and at the end of production, and any defective items produced are either sold at a discounted price or reworked/ repaired at a cost. Using this approach, practitioners or first-year college students who lack knowledge of differential calculus may be able to find solutions to inventory problems more easily.
\end{abstract}

Keywords: Inventory control, EPQ, rework, algebraic approach, differential calculus

JEL Classification: D20, D29

Öz

Birçok araştırmacı, optimal sipariş miktarı veya optimal üretim miktarının kapalı formda matematiksel eşitliklerini elde etmek için birinci ve ikinci dereceden kısmi türevlere izin veren geleneksel hesaplama yöntemlerini kullanmaktadır. Ancak, bu çalışma, ürün tarama işleminin üretim sırasında ve üretim sonunda yürütüldüğü ve üretilen kusurlu ürünlerin indirimli fiyatla satıldığı ya da belirli bir maliyetle yeniden işlendiği/tamir edildiği bir kusurlu üretim envanter sisteminde, üretim parti hacmi belirleme probleminin çözümlerine cebirsel bir yaklaşım sunmaktadır. Diferansiyel hesabı bilmeyen uygulamacılar veya birinci sınıf üniversite öğrencileri bu yaklaşımı kullanarak, envanter problemlerine daha kolay çözümler bulabilecektir.

Anahtar Kelimeler: Stok kontrolü, EÜM, yeniden işleme/tamir etme, cebirsel yaklaşim, diferansiyel hesap JEL Sinıflaması: D20, D29

* Süleyman Demirel University, Faculty of Economics and Administrative Sciences, Department of Business Administration, harunozturk@sdu.edu.tr

To cite this article: Öztürk, H. (2019). The derivation of production lot sizing with imperfect quality, inspection and rework using an algebraic approach. Journal of Research in Business, 4(2), 93-110. 


\section{Introduction}

The traditional economic production quantity (EPQ) model is commonly used in the manufacturing sector for determining the optimal production quantity and the time for the next replenishment, in order to minimize total production inventory costs per unit of time. One of the key assumptions of the traditional EPQ model is that all items produced in a production run are of perfect quality. However, some defective items may be included in an ordered or produced lot due to original defects during production or damage during transportation, or other reasons. When this occurs, it is necessary to either rework defective items, reject them, or refund customers if they have already received the items. These situations not only incur substantial expense, but also incur quality-related expense. The unexpected presence of defective products in an inventory may lead to high operating costs. As a result, quality control is obviously critical to any inventory system and has significant managerial implications, including customer satisfaction and demand among other implications. Scholars have devised a number of analytical models related to quality issues to integrate the problem and study the implications of defective quality on lot sizes.

In practice, some or all defective items can be reworked; hence the overall inventory costs can be reduced significantly. In order to minimize total inventory costs, there have been a number of studies by researchers, including Rosenblatt and Lee (1986), Porteus (1986), Zhang and Gerchak (1990), Paknejad et al. (1995), Liu and Yang (1996), Urban (1998), Salameh and Jaber (2000), Hayek and Salameh (2001), Jamal et al. (2004), Maddah and Jaber (2008), Chen et al. (2008), Maddah et al. (2009), Cárdenas-Barrón (2009), Jaber et al. (2014), Öztürk et al. (2015), Nobil et al. (2016), MoussawiHaidar et al. (2016), Manna et al. (2017), among others. These studies investigated the effects on inventory control of inspection, the presence of defective items in a lot ordered or produced, and rework of defective items.

For example, Salameh and Jaber (2000) presented an economic order quantity (EOQ) model under random supply, in which each ordered lot contains defective items with a known probability density function. They assumed a 100\% inspection process, performed immediately on the accepted lot, with the defective items kept in stock until the end of the inspection process, when they are sold as a single batch at a discounted price.

Hayek and Salameh (2001) proposed a model to determine the optimal production quantity for a production inventory system which assumes production of defective items, which are reworked. Jaber et al. (2014) proposed an inventory model which considers reworking of defective items in a local repair store or selling of these defective items on a secondary market. Öztürk et al. (2015) analyzed the case where each accepted lot contains a random proportion of defective items and a portion of these items can be reworked at a regional distributer's site. Moussawi-Haidar et al. (2016) incorporated quality control, defective items, and rework into an EPQ model with different inspection costs. Later, Öztürk (2017) revisited Moussawi-Haidar et al.s (2016) inventory model with respect to the reworking of defective items identified during production and screening. 
Manna et al. (2017) developed a mathematical model to determine the optimum production quantity and production run time for an imperfect production process with advertisement-dependent demand. They assume that the production rate of defective items is a function of the production rate, and the inspection rate is less than or equal to the production rate and greater than the demand rate. Benkherouf and Omar (2017) proposed a time-varying demand function formulation for the optimal production-inventory model with reworking of defective items. To learn more about these models, please refer to Sarkar and Moon (2014), Tayyab and Sarkar (2016), and Taleizadeh (2018).

It has been the longstanding goal of academicians and researchers to establish new methods of solving problems. Many are frequently characterized by considerable complexity, which requires different techniques to solve the problems. Academicians and researchers have been greatly motivated to integrate different methods of optimizing inventory theory. Arguably, algebraic optimization has been considered the favored method of developing inventory models and has been the focus of much attention over the last two decades. Its popularity can be attributed to the necessity of knowing only simple factorization. An example would be completing a perfect trinomial and squared binomial, both considered elementary mathematics typical learned prior to high school.

The application of calculus by taking the first and second order partial derivatives of the objective function is the most popular approach to derive the EOQ/EPQ formula. However, people unfamiliar with calculus may not be able to understand the solution procedure easily. Following the paper of Grubbström (1996), who first introduced a different method of obtaining the EOQ by avoiding derivatives by transferring algebraically average costs per unit into a complex and laborious equilateral formula to easily obtain the minimal solution, a number of researchers have focused on easy solution methods for inventory models. For instance, by considering the issue of backlogging, Grubbström and Erdem (1999) were able to extend the prior result to the EOQ formula. CárdenasBarrón (2001) extended the algebraic method used in Grubbström and Erdem (1999), and derived the optimal values of the production quantity and the maximum backorder quantity of the classical production inventory model. In the author's opinion, algebraic optimization presents an alternate means of introducing high school students to inventory theory. Later, Yang and Wee (2002) derived algebraically an optimal policy for an integrated vendor-buyer inventory system without using differential calculus. Chung and Wee (2007) studied an optimal replenishment policy for a multiechelon integrated production inventory problem with backorder, using a simple algebraic method.

Minner's (2007) approach used algebraic optimization to compare costs. This is advantageous as it only requires understanding the limit concept and falls into the category of intermediate mathematics (e.g., mathematics learned during the final year of high school and during the first year of engineering or business undergraduate programs). Wee and Chung (2007) used an algebraic method to derive the optimal production lot size of an integrated single-vendor, single-buyer inventory problem with backorder, just-in-time delivery and inspection cost. Chiu (2008) derived the optimal production quantity and the optimal backorder quantity for an imperfect EPQ model with failures in rework using the same algebraic method as was used in Wee and Chung (2007). Teng et al. (2011) developed 
a minor correction in Wee and Chung's (2007) work related to the expression for the total cost of the integrated vendor-buyer inventory system.

Cárdenas-Barrón (2011) derived inventory models with backorders, considering both linear and fixed backordering costs, without derivatives. Chiu et al. (2012) extended an algebraic approach to the solution of an integrated production inventory problem. Chen et al. (2012) showed that the optimal production quantity and the expected total costs for an EPQ model with discontinuous inventory issuing policy and imperfect rework process can be obtained without derivatives. Teng and Hsu (2015) proposed an EPQ model for defective items without using derivatives, and considered different inspection rates to determine the optimum production quantity. Chung et al. (2017) adopted the differential calculus approach to get the optimal solution of production quantity and the number of shipments in an imperfect EPQ model with partial reworking. Chang and Ouyang (2017) employed an arithmetic-geometric mean inequality method to obtain the optimal production lot size in an imperfect production inventory model with rework and shortages. In addition, Ronald et al. (2004), Sphicas (2006), Teng (2009), Teng et al. (2013), Sarkar (2013), Sarkar et al. (2016), Seliaman et al. (2018), and Lin (2019) investigated inventory models without derivatives.

The above-mentioned papers by Moussawi-Haidar et al. (2016) and Öztürk (2017) find the optimal production quantity by taking the derivative of the expected total profit function. However, this paper extends an algebraic approach to the solutions of the production inventory models proposed by Moussawi-Haidar et al. (2016) and Öztürk (2017) which take into account the inspection time, different inspection costs and rework of a random proportion of defective items.

\section{Problem Description and Modeling}

Moussawi-Haidar et al. (2016) studied a joint production lot sizing and inspection policy under an imperfect production inventory model in which a random proportion of items are defective, and these defective items are either sold or reworked. The description of the problem is as follows. A machine produces a single item with a production rate $a$, and the demand rate for the item is $\beta$; $\alpha>\beta$. During production, a random proportion $F$ of defective items is generated with a known probability distribution, and demand is met only from good items, which requires a quality control before items are sold to customers. When an item is found to be defective, it must be replaced with a good item. This implies that the inspection rate is the same as the demand rate before production ends. After production ends, inspection of the remaining items of the produced lot is conducted at a rate $x$ per unit of time; $x>\beta$.

They analyzed two inventory models. In the first model, defective items are sold as a single batch at a discounted price at the end of the inspection process. In the second model, defective items are reworked at a constant rework rate at the end of the inspection process. The same notation and assumptions are taken as Moussawi-Haidar et al. (2016):

- $a$ : Production rate per unit time 
- $\beta$ : Demand rate of the final product per unit time

- $\alpha_{1}$ : Rework rate of defective items per unit time, $\alpha_{1}<\beta$

- $\quad y \quad$ : Total number of items produced during a production cycle

- $T$ : Production cycle length

- $z_{1}$ : The maximum level of on-hand inventory of good items in units, when production process ends

- $z_{2}$ : The level of on-hand inventory of good items in units, when the inspection after production ends

- $z_{3}$ : The level of on-hand inventory of good items in units, when the defective items are subtracted from inventory or the rework process ends

- $K$ : Fixed production setup cost

- $F$ : Random proportion of defective items, with probability density function $f(P)$

- $x$ : Inspection rate per unit per unit time

- $d$ : Production rate of defective items per unit time

- $d_{1}$ : Inspection cost per item during production

- $d_{2}$ : Inspection cost per item after production ends

- $h$ : Holding cost per unit per unit time

- $h_{1}$ : Holding cost of defective items which will be reworked per unit per unit time

- $s$ : Unit selling price of good quality items

- $v$ : Unit selling price of defective items

- $c_{p}$ : Unit production cost

- $c_{\gamma}$ : The rework cost per unit

The assumptions considered to develop the mathematical models are

1. Shortages are not allowed.

2. The production rate is greater than the demand rate, $\alpha>\beta$.

3. The demand during production is met from good items only.

4. The inspection rate is greater than the demand rate, $x>\beta$. 
5. The inspection cost during production is higher than that after production, $d_{1}>d_{2}$.

6. The holding cost of the defective items being reworked is greater than that of good items, $h_{1}>h$.

7. The defective items are reworked at the end of the inspection process at a cost.

\subsection{Model 1: Defective Items are Sold as a Single Batch}

This model assumes that, upon completion of the inspection process, the defective items of $P$ y units are sold as a single batch at a discounted price of $v$ per unit. The behavior of the inventory level in a production cycle is shown in Figure 1, where:

$T$ is cycle length; $T=(1-P) y / \beta$

$t_{1}$ is the production run time; $t_{1}=y / a$,

$t_{2}$ is the time period required to inspect the remaining items of the produced lot,

$t_{3}$ is the time period to consume all on-hand inventory stock after the inspection.

Moussawi-Haidar et al. (2016) assumed that $N(y, P) \geq \beta t_{1}$, or equivalently $P \leq 1-\beta / a$, to avoid shortages during production. They also assumed that the time duration $t_{2}$ must be finished before the end of the cycle, i.e., $t_{2}<t_{3}$. Under the notation and assumptions, they derived the expected total profit per cycle as

$$
\begin{aligned}
& T P(y)=s(1-P) y+v P y \\
& -\left[K+c_{p} y+d_{1} \frac{\beta}{(1-P)} \frac{y}{\alpha}+d_{2} y\left(1-\frac{\beta}{\alpha}-\frac{P \beta}{\alpha(1-P)}\right)\right. \\
& \left.+h y^{2}\left(\frac{(1-P-\beta / \alpha)^{2}}{2 \beta}+\frac{1-\beta / \alpha}{2 \alpha}+\frac{P\left(1-\frac{\beta}{\alpha}-\frac{P \beta}{\alpha(1-P)}\right)}{x}\right)\right]
\end{aligned}
$$

Using the renewal theory, they found the expected total profit per unit of time as follows:

$$
\begin{aligned}
& E(T P U(y))=s \beta+\frac{v \beta E(P)}{1-E(P)} \\
& -\left[\frac{K \beta}{y(1-E(P))}+\frac{c_{p} \beta}{1-E(P)}+\frac{d_{1} \beta^{2}}{\alpha(1-E(P))} E\left(\frac{1}{1-P}\right)+\frac{d_{2} \beta}{(1-E(P))}\left(1-\frac{\beta}{\alpha}-\frac{\beta}{\alpha} E\left(\frac{P}{1-P}\right)\right)\right. \\
& \left.+\frac{h y}{(1-E(P))}\left(\frac{E\left((1-P-\beta / \alpha)^{2}\right)}{2}+\frac{\beta(1-\beta / \alpha)}{2 \alpha}+\frac{\beta E(P)\left(1-\frac{\beta}{\alpha}-\frac{\beta}{\alpha} E\left(\frac{P}{1-P}\right)\right)}{x}\right)\right]
\end{aligned}
$$




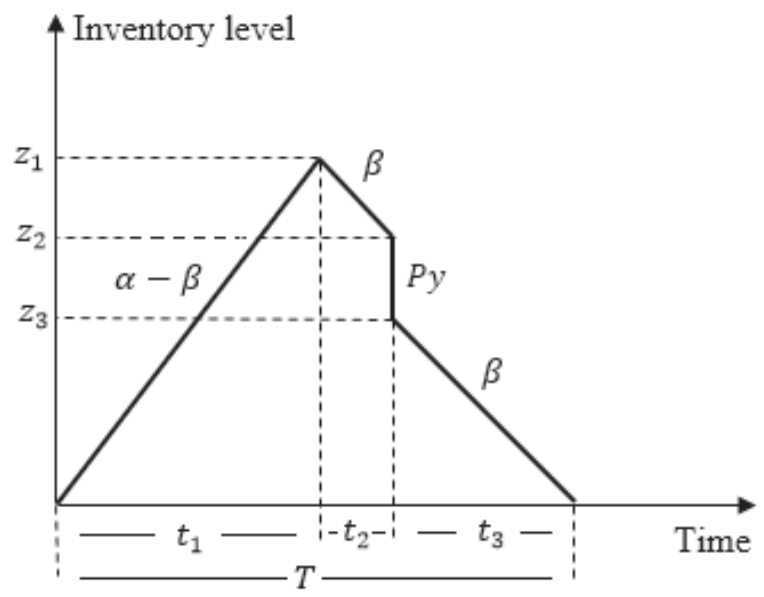

Figure 1. Inventory level over time

The expected value expression of the term $(1-P-\beta / \alpha)^{2}$ in the expected total profit function can be simplified to

$$
\begin{aligned}
& E\left((1-P-\beta / \alpha)^{2}\right)=E\left(((1-\beta / \alpha)-P)^{2}\right)=E\left((1-\beta / \alpha)^{2}-2 P(1-\beta / \alpha)+P^{2}\right) \\
& =(1-\beta / \alpha)^{2}-2 E(P)(1-\beta / \alpha)+E\left(P^{2}\right)
\end{aligned}
$$

Then, the expected total profit per unit of time is given as

$$
\begin{aligned}
& E(T P U(y))=s \beta+\frac{v \beta E(P)}{1-E(P)} \\
& -\left[\frac{K \beta}{y(1-E(P))}+\frac{c_{p} \beta}{1-E(P)}+\frac{d_{1} \beta^{2}}{\alpha(1-E(P))} E\left(\frac{1}{1-P}\right)+\frac{d_{2} \beta}{(1-E(P))}\left(1-\frac{\beta}{\alpha} E\left(\frac{1}{1-P}\right)\right)\right. \\
& \left.+\frac{h y}{(1-E(P))}\left(\frac{(1-\beta / \alpha)(1-2 E(P))}{2}+\frac{E\left(P^{2}\right)}{2}+\frac{\beta E(P)\left(1-\frac{\beta}{\alpha} E\left(\frac{1}{1-P}\right)\right)}{x}\right)\right]
\end{aligned}
$$

\subsection{Model 2: Defective Items are Reworked at A Constant Rework Rate}

In this model, as soon as the inspection process is completed, the defective items of $P$ y units are reworked to make them as-good-as-perfect at a constant rework rate $\alpha_{1}$, with $\alpha_{1}<\beta$. 


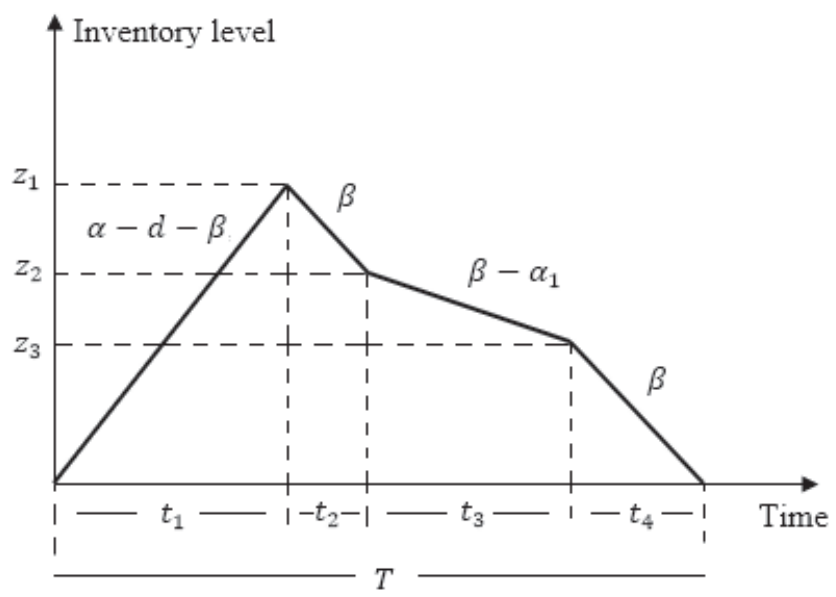

Figure 2. On-hand inventory level of good items

Figures 2 and 3 depict the behavior of the on-hand inventory levels of good items and defective items, respectively, where:

$T$ is cycle length,

$T=y / \beta$,

$t_{1}$ is the production run time, $t_{1}=y / a$,

$t_{2}$ is the time period required to inspect the remaining items of the produced lot,

$t_{3}$ is the time period needed to rework the defective items,

$t_{4}$ is the time period to consume all on-hand inventory stock after the rework.

It is assumed that the time duration $t_{2}$ must be finished before the end of the cycle, i.e., $t_{2}<t_{3}+t_{4}$.

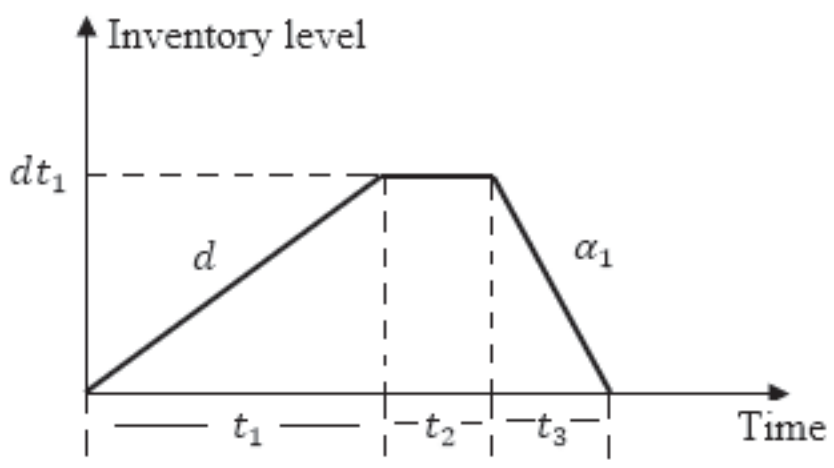

Figure 3. On-hand inventory level of defective items 
Under the notation and assumptions above, Öztürk (2017) revisited the model and derived the expected total profit per unit of time as

$$
\begin{gathered}
E(T P U(y))=S \beta \\
-\left\{\frac{K \beta}{y}+C_{p} \beta+C_{r} \beta E(P)+\frac{d_{1} \beta^{2}}{\alpha} E\left(\frac{1}{1-P}\right)+d_{2} \beta j\right. \\
+h y\left[\frac{\beta}{2 \alpha}\left(1-\frac{\beta}{\alpha}\right)+\frac{1}{2}\left(\left(1-\frac{\beta}{\alpha}\right)^{2}+\frac{\beta^{2}}{x^{2}}\right)-\frac{\beta j^{2}}{2 x}+E(P)\left(J-\frac{\beta j}{x}\right)\right. \\
+\frac{1}{2}\left(E\left(P^{2}\right)-2 E(P)\left(1-\frac{\beta}{\alpha}\right)-\frac{2 \beta^{3}}{x^{2} \alpha} E\left(\frac{1}{1-P}\right)+\frac{\beta^{4}}{x^{2} \alpha^{2}} E\left(\frac{1}{(1-P)^{2}}\right)\right) \\
\left.+\frac{\beta E(P) j}{x}-\frac{\left(\beta-\alpha_{1}\right) E\left(P^{2}\right)}{2 \alpha_{1}}\right] \\
\left.+\frac{h_{1} E\left(P^{2}\right) \beta y}{2 \alpha_{1}}\right\}
\end{gathered}
$$

where $J=1-E(P)-\frac{\beta}{\alpha}$ and $\tilde{J}=1-\frac{\beta}{\alpha} E\left(\frac{1}{1-P}\right)$.

\section{The Optimal Solution Using An Algebraic Approach}

Moussawi-Haidar et al. (2016) and Öztürk (2017) used derivatives to develop an EPQ model without backorders, and to derive the optimal production lot size $(y)$. Instead, we determine the optimal production quantity using an algebraic approach.

\subsection{Derivation of The Optimal Production Quantity (y) When Defective Items are Sold as a Single Batch}

The expected total profit per unit of time in Equation (4) is the expected total revenue per unit of time less the expected total cost per unit of time, and is given as

$$
\begin{gathered}
E(T P U(y))=s \beta+\frac{v \beta E(P)}{1-E(P)}-E\left(T C U(y)^{\prime}\right. \\
=s \beta+\frac{v \beta E(P)}{1-E(P)} \\
-\left[\frac{K \beta}{y(1-E(P))}+\frac{c_{p} \beta}{1-E(P)}+\frac{d_{1} \beta^{2}}{\alpha(1-E(P))} E\left(\frac{1}{1-P}\right)+\frac{d_{2} \beta}{(1-E(P))}\left(1-\frac{\beta}{\alpha} E\left(\frac{1}{1-P}\right)\right)\right. \\
\left.+\frac{h y}{(1-E(P))}\left(\frac{(1-\beta / \alpha)(1-2 E(P))}{2}+\frac{E\left(P^{2}\right)}{2}+\frac{\beta E(P)\left(1-\frac{\beta}{\alpha} E\left(\frac{1}{1-P}\right)\right)}{x}\right)\right]
\end{gathered}
$$


Since the revenue is independent of the production quantity $(y)$, maximizing the expected total profit per unit of time is equivalent to minimizing the expected total cost per unit of time. After some algebraic development, we can simplify $E(T C U(y)$ ') as follows:

$$
\begin{gathered}
E(T C U(y))=\left[\frac{c_{p} \beta}{1-E(P)}+\frac{d_{1} \beta^{2}}{\alpha(1-E(p))} E\left(\frac{1}{1-P}\right)+\frac{d_{2} \beta}{(1-E(p))}\left(1-\frac{\beta}{\alpha} E\left(\frac{1}{1-P}\right)\right)\right] \\
\quad+\left[\frac{K \beta}{(1-E(P))}\right] \times y^{-1} \\
+\left[\frac{h}{(1-E(P))}\left(\frac{(1-\beta / \alpha)(1-2 E(P))}{2}+\frac{E\left(p^{2}\right)}{2}+\frac{\beta E(p)\left(1-\frac{\beta}{\alpha} E\left(\frac{1}{1-P}\right)\right)}{x}\right)\right] \times y
\end{gathered}
$$

Let

$$
\begin{gathered}
\varphi_{1}=\frac{c_{p} \beta}{1-E(p)}+\frac{d_{1} \beta^{2}}{\alpha(1-E(p))} E\left(\frac{1}{1-p}\right)+\frac{d_{2} \beta}{(1-E(p))}\left(1-\frac{\beta}{\alpha} E\left(\frac{1}{1-P}\right)\right)>0 . \\
\varphi_{2}=\frac{K \beta}{(1-E(p))}>0, \\
\varphi_{3}=\frac{h}{(1-E(p))}\left(\frac{(1-\beta / \alpha)(1-2 E(p))}{2}+\frac{E\left(p^{2}\right)}{2}+\frac{\beta E(P)\left(1-\frac{\beta}{\alpha} E\left(\frac{1}{1-P}\right)\right)}{x}\right)>0 .
\end{gathered}
$$

Substituting $\varphi_{1}, \varphi_{2}$ and $\varphi_{3}$ in Equation (7), we have

$$
E(T C U(y))=\varphi_{1}+\varphi_{2} y^{-1}+\varphi_{3} y E(T C U(y))=\varphi_{1}+\varphi_{2} y^{-1}+\varphi_{3} y
$$

The algebraic method demonstrates that $\phi_{1} x+\phi_{2} / x+\phi_{3}$, with $\phi_{1}, \phi_{2}$ and $\phi_{3}$ positive, can be recalculated as (refer to Cárdenas-Barrón (2011) for further details)

$$
\begin{gathered}
f(x)=\phi_{1} x+\frac{\phi_{2}}{x}+\phi_{3}=\frac{\phi_{1}}{x}\left(x^{2}+\frac{\phi_{2}}{\phi_{1}}-2 x \sqrt{\frac{\phi_{2}}{\phi_{1}}}+2 x \sqrt{\frac{\phi_{2}}{\phi_{1}}}\right)+\phi_{3} \\
=\frac{\phi_{1}}{x}\left(x^{2}+\frac{\phi_{2}}{\phi_{1}}-2 x \sqrt{\frac{\phi_{2}}{\phi_{1}}}\right)+2 \sqrt{\phi_{1} \phi_{2}}+\phi_{3} \\
=\frac{\phi_{1}}{x}\left(x-\sqrt{\frac{\phi_{2}}{\phi_{1}}}\right)^{2}+2 \sqrt{\phi_{1} \phi_{2}}+\phi_{3} .
\end{gathered}
$$

Comparatively,

$$
f(x)=x\left(\frac{\sqrt{\phi_{2}}}{x}-\sqrt{\phi_{1}}\right)^{2}+2 \sqrt{\phi_{1} \phi_{2}}+\phi_{3}
$$


Since the non-negative square term, $f(x)$ is always minimized for $x=\sqrt{\phi_{2} / \phi_{1}}$, which reaches the minimum at $f(x)=2 \sqrt{\phi_{1} \phi_{2}}+\phi_{3}$.

Equation (8) indicates $\phi_{1} x+\phi_{2} / x+\phi_{3}$. Rearranging Equation (8), we obtain

$$
\begin{gathered}
E(T C U(y))=\varphi_{1}+y\left[\varphi_{2} y^{-2}+\varphi_{3}\right] \\
=\varphi_{1}+y\left(\sqrt{\varphi_{2}} y^{-1}-\sqrt{\varphi_{3}}\right)^{2}+2 \sqrt{\varphi_{2}} \sqrt{\varphi_{3}}
\end{gathered}
$$

Moreover, the proportion of defective items $F$ is a random variable with a known probability distribution. As discussed in Chung (2013), we assume $0 \leq E(P) \leq 1 /$. Since the terms $\varphi_{1}$ $, \varphi_{2}, \varphi_{3}$ and $\left(\sqrt{\varphi_{2}} y^{-1}-\sqrt{\varphi_{3}}\right)^{2}$ in Equation (9) are positive, then the function $E(\operatorname{TCU}(y)$ ), is positive for all $y>0$. From Equation (9), it can be noted that $E(T C U(y)$, and ( $E(T P U(y)$, have an optimum value if the square term, $\left(\sqrt{\varphi_{2}} y^{-1}-\sqrt{\varphi_{3}}\right)^{2}$, equals zero. That is

$$
\left(\sqrt{\varphi_{2}} y^{-1}-\sqrt{\varphi_{3}}\right)^{2}=0
$$

This yields

$$
y^{*}=\sqrt{\frac{\varphi_{2}}{\varphi_{s}}}
$$

Substituting $\varphi_{2}$ and $\varphi_{3}$ in Equation (11), the optimal production quantity $y^{*}$ is obtained as

$$
y^{*}=\sqrt{\frac{K \beta}{h\left[\frac{(1-\beta / \alpha)(1-2 E(P))}{2}+\frac{E\left(P^{2}\right)}{2}+\frac{\beta E(P)\left(1-\frac{\beta}{\alpha} E\left(\frac{1}{1-P}\right)\right)}{x}\right]}}
$$

and the expected total cost per unit of time $E\left(T C U\left(y^{*}\right)\right)$ is reduced to

$$
E\left(T C U\left(y^{*}\right)\right)=\varphi_{1}+2 \sqrt{\varphi_{2}} \sqrt{\varphi_{3}}
$$

The optimal production quantity in Equation (12) is the same equation as that obtained in MoussawiHaidar et al. (2016).

\subsection{Derivation of The Optimal Production Quantity $(\boldsymbol{y})$ When Defective Items are Reworked at a Constant Rework Rate}

The expected total profit per unit of time in Equation (5) is the expected total revenue per unit of time less the expected total cost per unit of time, and is given as 


$$
\begin{gathered}
E(T P U(y))=s \beta-E(T C U(y)) \\
=s \beta-\left\{\frac{K \beta}{y}+c_{p} \beta+C_{r} \beta E(P)+\frac{d_{1} \beta^{2}}{\alpha} E\left(\frac{1}{1-P}\right)+d_{2} \beta j\right. \\
+h y\left[\frac{\beta}{2 \alpha}\left(1-\frac{\beta}{\alpha}\right)+\frac{1}{2}\left(\left(1-\frac{\beta}{\alpha}\right)^{2}+\frac{\beta^{2}}{x^{2}}\right)-\frac{\beta y^{2}}{2 x}+E(P)\left(J-\frac{\beta j}{x}\right)+\frac{\beta E(P) j}{x}\right. \\
\left.+\frac{1}{2}\left(E\left(P^{2}\right)-2 E(P)\left(1-\frac{\beta}{\alpha}\right)-\frac{2 \beta^{3}}{x^{2} \alpha} E\left(\frac{1}{1-P}\right)+\frac{\beta^{4}}{x^{2} \alpha^{2}} E\left(\frac{1}{(1-P)^{2}}\right)\right)-\frac{\left(\beta-\alpha_{1}\right) E\left(p^{2}\right)}{2 \alpha_{1}}\right] \\
\left.+\frac{h_{1} E\left(P^{2}\right) \beta y}{2 \alpha_{1}}\right\}
\end{gathered}
$$

where $J=1-E(P)-\frac{\beta}{\alpha}$ and $\tilde{J}=1-\frac{\beta}{\alpha} E\left(\frac{1}{1-P}\right)$.

In a similar manner, rearranging $E(T C U(y)$, based on different forms of decision variable $y$, we obtain

$$
\begin{gathered}
E(T C U(y))=\left[c_{p} \beta+C_{r} \beta E(P)+\frac{d_{1} \beta^{2}}{\alpha} E\left(\frac{1}{1-P}\right)+d_{2} \beta \tilde{J}\right]+[K \beta] \times y^{-1} \\
+\left[\begin{array}{c}
\frac{\beta}{2 \alpha}\left(1-\frac{\beta}{\alpha}\right)+\frac{1}{2}\left(\left(1-\frac{\beta}{\alpha}\right)^{2}+\frac{\beta^{2}}{x^{2}}\right)-\frac{\beta \tilde{J}^{2}}{2 x}+E(P)\left(J-\frac{\beta \tilde{J}}{x}\right)+\frac{\beta E(P) \tilde{J}}{x} \\
\left.+\frac{1}{2}\left(E\left(P^{2}\right)-2 E(P)\left(1-\frac{\beta}{\alpha}\right)-\frac{2 \beta^{3}}{x^{2} \alpha} E\left(\frac{1}{1-p}\right)+\frac{\beta^{4}}{x^{2} \alpha^{2}} E\left(\frac{1}{(1-P)^{2}}\right)\right)-\frac{\left(\beta-\alpha_{1}\right) E\left(p^{2}\right)}{2 \alpha_{1}}\right) \\
+\frac{h_{1} E\left(p^{2}\right) \beta}{2 \alpha_{1}}
\end{array}\right] \times y
\end{gathered}
$$

Let

$$
\begin{gathered}
\xi_{1}=c_{p} \beta+C_{r} \beta E(P)+\frac{d_{1} \beta^{2}}{\alpha} E\left(\frac{1}{1-P}\right)+d_{2} \beta \tilde{J}>0 \\
\xi_{2}=K \beta>0 \\
\xi_{3}=h\left[\frac{\beta}{2 \alpha}\left(1-\frac{\beta}{\alpha}\right)+\frac{1}{2}\left(\left(1-\frac{\beta}{\alpha}\right)^{2}+\frac{\beta^{2}}{x^{2}}\right)-\frac{\beta J^{2}}{2 x}+E(P)\left(J-\frac{\beta \jmath}{x}\right)+\frac{\beta E(P) j}{x}\right. \\
\left.+\frac{1}{2}\left(E\left(P^{2}\right)-2 E(P)\left(1-\frac{\beta}{\alpha}\right)-\frac{2 \beta^{3}}{x^{2} \alpha} E\left(\frac{1}{1-P}\right)+\frac{\beta^{4}}{x^{2} \alpha^{2}} E\left(\frac{1}{(1-P)^{2}}\right)\right)-\frac{\left(\beta-\alpha_{1}\right) E\left(p^{2}\right)}{2 \alpha_{1}}\right] \\
+\frac{h_{1} E\left(p^{2}\right) \beta}{2 \alpha_{1}}
\end{gathered}
$$

Substituting $\xi_{1}, \xi_{2}$ and $\xi_{3}$ in Equation (15), we have 


$$
E(T C U(y))=\xi_{1}+\xi_{2} y^{-1}+\xi_{3} y
$$

Equation (16) indicates $\phi_{1} x+\phi_{2} / x+\phi_{3}$. Rearranging Equation (16), we obtain

$$
\begin{gathered}
E(\operatorname{TCU}(y))=\xi_{1}+y\left[\xi_{2} y^{-2}+\xi_{3}\right] \\
=\xi_{1}+y\left(\sqrt{\xi_{2}} y^{-1}-\sqrt{\xi_{3}}\right)^{2}+2 \sqrt{\xi_{2}} \sqrt{\xi_{3}}
\end{gathered}
$$

The terms $\xi_{1}, \xi_{2}$ and $\left(\sqrt{\xi_{2}} y^{-1}-\sqrt{\xi_{3}}\right)^{2}$ in Equation (9) are positive. The function $E(T C U(y)$, is positive for all $y>0$, if the term $\xi_{3}>0$. Although the positiveness of the term $\xi_{3}$ cannot be proven, the numerical examples presented in Section 4 indicate that the term $\xi_{3}$ is positive.

From Equation (17), it can be noted that $E(T C U(y)$ ), and $(E(T P U(y))$ have an optimum value if the square term, $\left(\sqrt{\xi_{2}} y^{-1}-\sqrt{\xi_{3}}\right)^{2}$, equals zero. That is

$$
\left(\sqrt{\xi_{2}} y^{-1}-\sqrt{\xi_{3}}\right)^{2}=0
$$

This yields

$$
y^{*}=\sqrt{\frac{\xi_{2}}{\xi_{s}}}
$$

Substituting $\xi_{2}$ and $\xi_{3}$ in Equation (19), the optimum production quantity $y^{*}$ is obtained as

$$
y^{*}=\sqrt{\frac{K \beta}{\left[\begin{array}{c}
\frac{\beta}{2 \alpha}\left(1-\frac{\beta}{\alpha}\right)+\frac{1}{2}\left(\left(1-\frac{\beta}{\alpha}\right)^{2}+\frac{\beta^{2}}{x^{2}}\right)-\frac{\beta)^{2}}{2 x}+E(P)\left(J-\frac{\beta \gamma}{x}\right)+\frac{\beta E(P)\}}{x} \\
\left.+\frac{1}{2}\left(E\left(P^{2}\right)-2 E(P)\left(1-\frac{\beta}{\alpha}\right)-\frac{2 \beta^{3}}{x^{2} \alpha} E\left(\frac{1}{1-P}\right)+\frac{\beta^{4}}{x^{2} \alpha^{2}} E\left(\frac{1}{(1-P)^{2}}\right)\right)-\frac{\left(\beta-\alpha_{1}\right) E\left(P^{2}\right)}{2 \alpha_{1}}\right]+\frac{h_{1} E\left(P^{2}\right) \beta}{2 \alpha_{1}}
\end{array}\right.}} .
$$

and the expected total cost per unit of time $E\left(T C U\left(y^{*}\right)\right)$ becomes

$$
E\left(T C U\left(y^{*}\right)\right)=\xi_{1}+2 \sqrt{\xi_{2}} \sqrt{\xi_{3}}
$$

The optimal production quantity in Equation (20) is the same equation as that obtained in Öztürk (2017). 


\section{Numerical Examples}

\subsection{Example 1 (Model 1: Defective Items are sold as A Single Batch)}

The theory can be validated using the numerical parameters adopted from Moussawi-Haidar et al. (2016). Take a constant demand rate of $\beta=1200$ units/year, and a production rate of $\alpha=1600$ units/ year. Assume also a production cost per unit of $c_{p}=\$ 104$, selling price of non-defective items at $s=$ $\$ 200$ / unit, and discount price of defective items at $v=\$ 80 /$ unit. Allow an annual screening rate of $x$ $=175,200$ units. Screening during production has a cost per item of $d_{1}=\$ 0.6$ and post-production screening cost per item is $d_{2}=\$ 0.5$. The production setup cost $K=\$ 1500$. The cost of holding nondefective items is $h=\$ 20 /$ unit/year. This study assumes that the proportion of defective items is uniformly distributed over the interval $[a, b]$ with $a=0$, and $b=0.1$. Then, the probability density function $f(P)$ is given as

$$
f(P)=\left\{\begin{array}{c}
10,0 \leq P \leq 0.1 \\
0, \text { otherwise }
\end{array}\right.
$$

From the probability density function given by Equation (22), the following expected value expressions can be calculated:

$$
\begin{gathered}
E(P)=\int_{a}^{b} P f(P) d P=\int_{0}^{0.1} 10 P d P=0.05, \\
E\left(P^{2}\right)=\int_{a}^{b} P^{2} f(P) d P=\int_{0}^{0.1} 10 P^{2} d P=0.003333, \\
E\left(\frac{1}{(1-P)^{2}}\right)=\int_{a}^{b}\left(\frac{1}{(1-P)^{2}}\right) f(P) d P=\int_{0}^{0.1} 10\left(\frac{1}{(1-P)^{2}}\right) d P=1.111111, \\
E\left(\frac{1}{1-P}\right)=\int_{a}^{b}\left(\frac{1}{1-P}\right) f(P) d P=\int_{0}^{0.1} 10\left(\frac{1}{1-P}\right) d P=1.053605,
\end{gathered}
$$

and

$$
E\left(\frac{P}{1-P}\right)=\int_{a}^{b}\left(\frac{P}{1-P}\right) f(P) d P=\int_{0}^{0.1} 10\left(\frac{P}{1-P}\right) d P=0.053605 .
$$

Substituting these values into $\varphi_{1}, \varphi_{2}$, and $\varphi_{3}$, we have

$$
\begin{aligned}
& \varphi_{1}=\frac{c_{p} \beta}{1-E(p)}+\frac{d_{1} \beta^{2}}{\alpha(1-E(P))} E\left(\frac{1}{1-P}\right)+\frac{d_{2} \beta}{(1-E(P))}\left(1-\frac{\beta}{\alpha} E\left(\frac{1}{1-P}\right)\right)=132086.786>0 \\
& \text { and } \\
& \qquad \varphi_{2}=\frac{K \beta}{(1-E(P))}=1894736.84>0
\end{aligned}
$$




$$
\varphi_{3}=\frac{h}{(1-E(P))}\left(\frac{(1-\beta / \alpha)(1-2 E(P))}{2}+\frac{E\left(p^{2}\right)}{2}+\frac{\beta E(P)\left(1-\frac{\beta}{\alpha} E\left(\frac{1}{1-P}\right)\right)}{x}\right)=2.40502136>0
$$

The solution of Equation (11), gives an optimal production quantity of $y^{*}=887.60$ units. We substitute this value into Equations (13) and (6), to calculate the total cost per year $E\left(T C U\left(y^{*}\right)\right)$ and maximum total profit per year $E\left(T P U\left(y^{*}\right)\right.$, respectively: $E\left(T C U\left(y^{*}\right)\right)=\$ 136,356.157$, and $E\left(T P U\left(y^{*}\right)\right)=\$ 108,696.475$.

\subsection{Example 2 (Model 2: Defective Items are reworked at A Constant Rework Rate)}

All parameters are kept the same as in Example 1. The following additional parameter values are used. The holding cost for defective items is $h_{1}=\$ 22 /$ unit/year. The rework rate for defective items is $\alpha_{1}=100$ units/year. The repair cost per defective item is $c_{r}=\$ 8$. Substituting these values into J $, \hat{j}, \xi_{1}, \xi_{2}$, and $\xi_{3}$, we have

$$
\begin{gathered}
J=1-E(P)-\frac{\beta}{\alpha}=0.2 . \\
\tilde{J}=1-\frac{\beta}{\alpha} E\left(\frac{1}{1-P}\right)=0.209796 \\
\xi_{1}=c_{p} \beta+C_{r} \beta E(P)+\frac{d_{1} \beta^{2}}{\alpha} E\left(\frac{1}{1-P}\right)+d_{2} \beta \tilde{J}=125974.8245>0, \\
\xi_{2}=K \beta=1800000>0,
\end{gathered}
$$

and

$$
\begin{gathered}
\xi_{3}=h\left[\frac{\beta}{2 \alpha}\left(1-\frac{\beta}{\alpha}\right)+\frac{1}{2}\left(\left(1-\frac{\beta}{\alpha}\right)^{2}+\frac{\beta^{2}}{x^{2}}\right)-\frac{\beta y^{2}}{2 x}+E(P)\left(J-\frac{\beta j}{x}\right)+\frac{\beta E(P) j}{x}\right. \\
\left.+\frac{1}{2}\left(E\left(P^{2}\right)-2 E(P)\left(1-\frac{\beta}{\alpha}\right)-\frac{2 \beta^{3}}{x^{2} \alpha} E\left(\frac{1}{1-P}\right)+\frac{\beta^{4}}{x^{2} \alpha^{2}} E\left(\frac{1}{(1-P)^{2}}\right)\right)-\frac{\left(\beta-\alpha_{1}\right) E\left(p^{2}\right)}{2 \alpha_{1}}\right] \\
+\frac{h_{1} E\left(p^{2}\right) \beta}{2 \alpha_{1}}=2.553673>0 .
\end{gathered}
$$

The solution of Equation (19) gives an optimal production quantity of $y^{*}=839.56$ units. We substitute this value into Equations (21) and (14) to calculate the total cost per year $E\left(T C U\left(y^{*}\right)\right)$ and the maximum total profit per year $E\left(T P U\left(y^{*}\right)\right.$ ) respectively: $E\left(T C U\left(y^{*}\right)\right)=\$ 130,262.766$ , and $E\left(T P U\left(y^{*}\right)\right)=\$ 109,737.234$. Finally, our findings from Equations 6 and 21 give the same results as those obtained by Moussawi-Haidar et al. (2016) and Öztürk (2017) from their Equations 13 and 31 . This illustrates the validity of our simplification. 


\section{Conclusion}

In the majority of literature studied, the impact of screening seems to be ignored in reference to economic order and production quantity models with imperfect production and reworking procedures. The models presume that screening continually occurs during production and that reworking commences at the conclusion of productions periods. This paper analyzed two EPQ models, which evaluated defective items during the production and screening process in different ways. In the real world of production environments, economic necessity mandates a) the sale of defective items at the conclusion of the screening period; b) constant reworking of these items. We used an algebraic approach to solve the imperfect production quantity models developed by Moussawi-Haidar et al. (2016) and Öztürk (2017). However, the aforementioned studies did not address these types of situations. Using this approach allows better understanding of inventory models for those with limited knowledge of calculus, and enables the optimal production quantity in addition to optimal total costs per time unit to calculate a realistic EPQ model without using derivatives. Mathematical examples were provided to confirm theoretical results. Finally, the algebraic approach can be applied to production inventory models with shortages and fully backordered.

\section{References}

Benkherouf, L., \& Mohamed, O. (2017). Optimal manufacturing batch size with rework for a finite-horizon and time-varying demand rates inventory model. RAIRO-Operations Research, 57(1), 173-187.

Cárdenas-Barrón, L.E. (2001). The economic production quantity (EPQ) with shortage derived algebraically. International Journal of Production Economics, 70, 289-292.

Cárdenas Barrón, L.E. (2009). Economic production quantity with rework process at a single-stage manufacturing system with planned backorders. Computers \& Industrial Engineering, 57, 1105-1113.

Cárdenas-Barrón, L.E. (2011). The derivation of EOQ/EPQ inventory models with two backorders costs using analytic geometry and algebra. Applied Mathematical Modelling, 35, 2394-2407.

Chen, C. K., Lo, C. C., \& Liao, Y. X. (2008). Optimal lot size with learning consideration on an imperfect production system with allowable shortages. International Journal of Production Economics, 113(1), $459-469$.

Chen K. - K., Wu, M. - F., Chiu, S.W., \& Lee, C. - H. (2012). Alternative approach for solving replenishment lot size problem with discontinuous issuing policy and rework. Expert Systems with Applications, 39, 2232 2235.

Chiu, S. W. (2008). "Production lot size problem with failure in repair and backlogging derived without derivatives", European Journal of Operational Research, 188, 610-615.

Chiu, S. W., Chen, K. - K., \& Chiu, Y.-S. P. (2012). Notes on the mathematical modelling approach used to determine the replenishment policy for the EMQ model with rework and multiple shipments. Applied Mathematics Letters, 25, 1964-1968.

Chung, C. J., \& Wee, H. M. (2007). Optimizing the economic lot size of a three-stage supply chain with backordering derived without derivatives. European Journal of Operational Research, 183, 933-943.

Chung, K.-J. (2013). The algorithm to locate the optimal solution for production system subject to random machine breakdown and failure in rework for supply chain management. Journal of Optimization Theory and Applications, 158(3), 888-895, (2013). 
Chung, K. - J., Ting, P. - Sh., Cárdenas Barrón, L.E. (2017). A simple solution procedure for solving the multidelivery policy into economic production lot size problem with partial rework. Scientia Iranica E, 24(5), 2640-2644.

Grubbström, R.W. (1996). Material requirements planning and manufacturing resource planning. In: International Encyclopedia of Business and Management, vol. 4. Routledge, London, pp. 3400-3420.

Grubbström, R.W., \& Erdem, A. (1999). The EOQ with backlogging derived without derivatives. International Journal of Production Economics, 59, 529-530.

Hayek, P. A., \& Salameh, M.K. (2001). Production lot sizing with the reworking of imperfect quality items produced. Production Planning and Control, 12(6), 584-590.

Jaber, M. Y., Zanoni, S., \& Zavanella, L.E. (2014). Economic order quantity model for imperfect items with buy and repair options. International Journal of Production Economics, 155, 126-131.

Jamal, A. M. M., Sarker, B. R., \& Mondal, S. (2004). Optimal manufacturing batch size with rework process at a single stage production system. Computers \& Industrial Engineering, 47(1), 77-89.

Lin, S. S.-C. (2019). Note on "The derivation of EOQ/EPQ inventory models with two backorders costs using analytic geometry and algebra”. Applied Mathematical Modelling, 73, 378-386.

Liu, J. J., \& Yang, P. (1996). Optimal lot-sizing in an imperfect production system with homogeneous reworkable jobs. European Journal of Operational Research, 91, 517-527.

Maddah, B., Salameh, M. K., \& Karame, G.M. (2009). Lot sizing with random yield and different qualities. Applied Mathematical Modelling, 33(4), 1997-2009.

Maddah, B., \& Jaber, M.Y. (2008). Economic order quantity for items with imperfect quality: Revisited. International Journal of Production Economics, 112 (2), 808-815.

Manna, A. K., Dey, J. K., \& Mondal, S.K. (2017). Imperfect production inventory model with production rate dependent defective rate and advertisement dependent demand. Computers \& Industrial Engineering, $104,9-22$.

Minner, S. (2007). A note on how to compute economic order quantities without derivatives by cost comparisons. International Journal of Production Economics, 105(1), 293-296.

Moussawi-Haidar, L., Salameh, M., \& Nasr, W. (2016). Production lot sizing with quality screening and rework. Applied Mathematical Modelling, 40, 3242-3256.

Nobil, A. H., Sedigh, A. H. A., \& Cárdenas Barrón, L.E. (2016). A multi-machine multi-product EPQ problem for an imperfect manufacturing system considering utilization and allocation decisions. Expert Systems with Applications, 56, 310-319.

Öztürk, H., Eroglu, A., \& Lee, G.M. (2015). An economic order quantity model for lots containing defective items with rework option. International Journal of Industrial Engineering, 22 (6), 683-704.

Öztürk, H. $(2017<<)$. A note on "Production lot sizing with quality screening and rework". Applied Mathematical Modelling, 43, 659-669.

Paknejad, M. J., Nasri, F., \& Affisco, J. F. (1995). Defective units in a continuous review (s, Q) system. International Journal of Production Research, 33(10), 2767-3777.

Porteus, E. L. (1986). Optimal lot sizing, process quality improvement and setup cost reduction. Operations Research, 34, 137-144.

Ronald, R., Yang, G. K., \&Chu, P. (2004). Technical note: The EOQ and EPQ models with shortages derived without derivatives. International Journal of Production Economics, 92, 197-200.

Rosenblatt, M. J., \& Lee, H.L. (1986). Economic production cycles with imperfect production processes. IIE Transactions, 18, 48-55. 
Salameh, M. K., \& Jaber, M.Y. (2000). Economic production quantity model for items with imperfect quality. International Journal of Production Economics, 64, 59-64.

Sarkar, B. (2013). A production-inventory model with probabilistic deterioration in two-echelon supply chain management. Applied Mathematical Modelling, 37(5), 3138-3151.

Sarkar, B., Ganguly, B., Sarkar, M., \& Pareek, S. (2016). Effect of variable transportation and carbon emission in a three-echelon supply chain model. Transportation Research Part E: Logistics and Transportation Review, 91, 112-128.

Sarkar, B., \& Moon, I. (2014). Improved quality, setup cost reduction, and variable backorder costs in an imperfect production process. International Journal of Production Economics, 155, 204-213.

Seliaman, M. E., Khan, M., \& Cárdenas-Barrón, L. E. (2018). Algebraic modelling of a two level supply chain with defective items. RAIRO-Operations Research, 52(2), 415-427.

Sphicas, G. P. (2006). EOQ and EPQ with linear and fixed backorder costs: Two cases identified and models analyzed without calculus. International Journal of Production Economics, 100, 59-64.

Taleizadeh, A. A. (2018). 'A constrained integrated imperfect manufacturing-inventory system with preventive maintenance and partial backordering'. Annals of Operations Research, 261(1-2), 303-337.

Tayyab, M., \& Sarkar, B. (2016). Optimal batch quantity in a cleaner multi-stage lean production system with random defective rate. Journal of Cleaner Production, 139, 922-934.

Teng J. - T., Cárdenas Barrón L. E., Lou, K. - R., \& Wee H. M. (2013). Optimal economic order quantity for buyer-distributor-vendor supply chain with backlogging derived without derivatives. International Journal of Systems Science, 44(5). 986-994.

Teng, H. - M., \& Hsu, P. - H. (2015). Optimal production lots for items with imperfect production and screening processes without using derivatives. International Journal of Management and Enterprise Development, 14(2), 172-184.

Teng, J. - T. (2009). A simple method to compute economic order quantities. European Journal of Operational Research, 198, 351-353.

Teng, J. - T., Cárdenas-Barrón, L. E., \& Lou, K. - R. (2011). The economic lot size of the integrated vendorbuyer inventory system derived without derivatives: A simple derivation. Applied Mathematics and Computation, 217, 5972-5977.

Urban, T. L. (1998). Analysis of production systems when run length influences product quality. International Journal of Production Research, 36(11), 3085-3094.

Wee, H. M., \& Chung, C. J. (2007). A note on the economic lot size of the integrated vendor-buyer inventory system derived without derivatives. European Journal of Operational Research, 177, 1289-1293.

Yang, P. C., \& Wee, H. M. (2002). The economic lot size of the integrated vendor-buyer inventory system derived without derivatives. Optımal Control Applications and Methods, 23, 163-169.

Zhang, X., \& Gerchak, Y. (1990). Joint lot sizing and inspection policy in an EOQ model with random yield. IIE Transactions, 22(1), 41-47. 